\title{
To understand the implications of finance on health benefits of financial security to health
}

\section{Introduction}

The dynamic relationship of one's financial and economic resources as they are applied to or impact the state of physical, mental and social well-being. In the traditional sense of the term, Investopedia defines Financial Health as: "A term used to describe the state of one's personal financial situation. There are many dimensions to financial health, including the amount of savings you have, how much you are setting away for retirement and how much of your income you are spending on fixed or non-discretionary expenses."

\section{Focus on financial health}

Health and finances are dynamic, always changing, in flux, up and down. Your personal financial situation can be unhealthy and the result of that can lead to problems in other areas of your life. Your personal health can be poor and that can lead to significant financial issues. So we want to help people focus on "Financial Health" and examine more closely how a person, family or organization uses their finances and economic resources and ultimately how their decisions, behaviors, routines and habits impact their overall well-being. "Your debt may cost you more than just interest. Research shows there's a clear link between your financial health and your mental health and your debt may serve as a tangible representation of your psychological state." Amy Morin, Psychotherapist, Forbes.

\section{Method used to review}

It states that a personal comfort of the person with his own finances determines The Financial Health of that individual; hence the outcome is very much individual and personal. It is determined by parameters like the goals set by the individual, the financial plan/strategy used and his risk appetite. ${ }^{1}$

Why financial health is defined as "The dynamic relationship of one's financial and economic resources as they are applied to or impact the state of physical, mental and social well-being."? "\{The World Health Organization, on the other hand, defines "Health" as: "A state of complete physical, mental and social well-being and not merely the absence of disease or infirmity." While in this definition, a person's financial situation is, at best, implied, the World Health Organization does further elaborate on this concept in their explanation of Health Promotion. Health Promotion is described as: "The process of enabling people to increase control over, and to improve, their health. To reach a state of complete physical, mental and social well-being (their definition of health), an individual or group must be able to identify and to realize aspirations, to satisfy needs, and to change or cope with the environment. Health is, therefore, seen as a resource for everyday life, not the objective of living. Health is a positive concept emphasizing social and personal resources, as well as physical capacities. Therefore, health promotion is not just the responsibility of the health sector, but goes beyond healthy life-styles to well-being. "? "

The Health Factor is in direct proportion to the comfort with money, the Finance factor, in terms of simple mathematics. Any

\author{
Volume 2 Issue 5 - 2018
}

\author{
Parvinder Kaur \\ Osmania University, India
}

Correspondence: Parvinder Kaur, Company Secretary, Osmania University, India, Email kparvander@gmail.com

Received: December 26, 2017| Published: October 16, 2018

discomfort in finance leads to increase in existing stress levels which has a some impact on health; initially it becomes a challenge. When sustained for longer durations the impact is usually negative with proportion to the deficits and the affordability of the individuals. Further, we have several resources for good health like good food (balanced diet), comfortable home, exercise etc. For everyday life we need a livelihood resource, a means of commuting e.g. car or bike, a good social network and several other things. One such thing included is good health which facilitates to maintain and /or achieve this. These factors are interdependent and resource of health (the health factor) can depreciate (have negative impact) if there is depreciation in food, clothing housing or any such resource. Hence, good health is resource to life and lifestyle. An objective is a goal set to achieve eg clearing an exam or buying an asset like car. Health is something we use to lead our day to day life, which enables us to achieve these objectives. When we understand Health promotion as stated above "to identify and to realize aspirations, to satisfy needs, and to change or cope with the environment". We realize an ability to acquire usually involves a cost. If the person can afford it easily, he is more comfortable than when he has to make arrangement for money. Here, the quotient comes in and that quotient is called "the capacity", the capacity or capability to withstand and sustain the deficit. It is also affected by the capacity of the individual to resolve the deficit. A good health enables us to generate this capacity, which acts as a precious resource towards life. Therefore, we understand that there is a direct relationship of health and comfort with finance or the health factor and the finance factor. ${ }^{2}$

Looking up further at the health promotion "health promotion is not just the responsibility of the health sector, but goes beyond healthy life-styles to well-being" we are able to adjudge on our decision to strive to be fit. The health sector is a segment of governance or financial investment or utilizations which help us stay well; it maybe by making establishments like hospitals, clinics or town planning, facility creations etc or setting up companies or factories that make medicines, testing machines etc and finally we use them e.g. we approach a clinic for treatment or we move out to park for jogging. Hence, a healthy lifestyle definitely enable us to stay fit but there are sometimes challenges to health when we fall ill e.g. common cold or cough. At that time we need to approach the health sector for treatment and restore the good health. We need to bear a cost which is in addition to the ongoing cost of living. Here, say there is burden of sudden hospitalization, and the person holds medical insurance, it sheds the burden of the cost of hospitalization (according 
to the policy) and provides financial relief. The relief felt would be in accordance to the amount that may be borne by the insurance. When in financial crunch the person gets the money, it definitely relieves. Once, the health restores we resume to our lifestyles and progress ourselves to continuous betterment so that we stay well. Therefore when we strive for better health, the health sector is not responsible for that promotion as much as our efforts that follow a lifestyle for good health and sustain the wellness/ fitness. Therefore, we contribute significantly to the health sector beyond the healthy lifestyles to wellbeing or being fit. $^{3}$

"Studies show that your financial health could be good indicator of your mental health." "Your debt may cost you more than just interest. Research shows there's a clear link between your financial health and your mental health and your debt may serve as a tangible representation of your psychological state." Writes Amy Morin in her review articles published with researches cited. Looking up the article and trying to understand the influence on the mental health. Let us lookup the proportionality again: the health factor is directly related to the finance factor, as we understood earlier in this article. The Finance factor when negative causes some impact on health in the form of stress, strain and agony(pain, discomfort etc), which is by convention deemed negative to good health. Hence, we understand that the finance factor is distributed into three parts stress factor eg worry, anxiety, the strain factor eg headache, acid peptic disease and the agony factor eg peptic ulcer or chest pain. When we again look up the health factor in these three different factors as stated the stress factor, the strain factor and the agony factor, the effect so that may result is cumulative of these factors. However, these are independent of each other as observed. ${ }^{4}$

\section{The observations to be noted are as follows:}

I. \$ Approximately one in five U.S. adults experiences a mental illness each year according to the National Institute of Mental Health (link is external). And multiple studies report people with mental health problems are more likely to be in debt.

II. \$ "Stress Factor" :

III. \#Researchers concluded the likelihood of having a mental health problem is three times higher among people who have debt. Depression, anxiety disorders and psychotic disorders were among the common mental illnesses people in debt experienced.

IV. \# Short-term debt may place people at the highest risk of depression. A study published in the Journal of Family and Economic Issues(link is external) found that unmarried people, people reaching retirement age, and those who are less educated were particularly vulnerable to the harmful effects of stress associated with credit cards and overdue bills.

V. \$ "Strain factor":

VI. \#A 2007 study published in Psychological Medicine (link is external) found that difficulty paying for housing has a major effect on mental well-being. The researchers concluded that people who struggle to pay for housing experience distress levels similar to someone experiencing divorce and job loss.

VII. \$ “Agony factor":

VIII. \# Researchers concluded the likelihood of having a mental health problem is three times higher among people who have debt. Depression, anxiety disorders and psychotic disorders were among the common mental illnesses people in debt experienced. There was an even higher link between suicide and debt. People who complete suicide are eight times more likely to be in debt.

IX. \#Short-term debt may place people at the highest risk of depression. A study published in the Journal of Family and Economic Issues(link is external) found that unmarried people, people reaching retirement age, and those who are less educated were particularly vulnerable to the harmful effects of stress associated with credit cards and overdue bills. ${ }^{5}$

Therefore, we observe that there is direct relation between the health and finance. The effect of health classified into three parts the stress, strain and agony have a cumulative effect on health independent of each other and may manifest as anxiety, depression or job loss depending on circumstances. We have also observed that education is an important factor and it has a cost to it. We also find unmarried people more prone, hence social support does have an impact. These are also somewhere affected by finances wherein the ability to bear the expenses of the lifestyle may have impact. So, there are clear observations to the costings and the ability to bear the costings which make up the financial status of that person which clearly in turn impacts the health of that person which determines his health status.

\section{Excerpt}

I. \$ A 2007 study published in Psychological Medicine (link is external) found that difficulty paying for housing has a major effect on mental well-being.

II. \$ There's also a good chance that debt and mental health problems fuel one another. Going into debt may increase your chance of a mental health problem, but a mental health problem may exacerbate your risk of falling deeper into debt. ${ }^{6}$

\section{0 steps to improve your financial health}

a. Spend less than you earn

b. Stick to a budget

c. Pay off the credit card

d. Have a savings plan

e. Invest

f. Understand your investments

g. Review your insurance

h. Update your will

i. Keep good records

j. Get financial advice

\section{Discussion}

Finance is huge segment that is largely classified as Earnings, Liquid assets eg investments like fixed deposits, Mutual Funds etc and assets or "net worth" which are usually fixed eg property, car, business etc. Earnings influence the day to day life style. Which is affected by savings and debts. Savings contribute to building assets and guarding against urgent needs. Some amount of debt is said to be good as it reduces immediate burden and can be paid of in parts eg EMI for 
a home or car. If the EMI is a nominal amount or earnings it boosts the confidence by shedding the burden but if the EMI is significant and takes more than $25 \%$ of earnings the outcome is usually a mental strain as reflected in studies. Most of such outcomes are calculated by several finance companies by a method called "risk profiling". When planning for retirement (PRP, Principal India) they strategically decide the allocation to Equity, Mutual Funds, Insurance and Assets. A young healthy adult with good risk appetite is usually encouraged to invest in Equities.

\section{Future scope}

Most of the financial dealings are age old and continuously developing. After insurance and capital markets, now people are looking up to take planned decisions towards allocation of money. The concepts spreading to the globe as Retirement planning, real estate planning or capital investment allocation in recommended shares or mutual funds or commodities or business. The area is booming and I enjoyed my journey to this exquisite revelations and hope to stay in the lap of luxury and pray the same for you.

\section{Conclusion}

There is significant influence of finance on health in different perspectives of human wellbeing: be it social, mental or body fitness. Several areas of the persons finance influence the health, which include the income, investments and the "net worth" of that individual.

\section{Acknowledgements}

None.

\section{Conflict of interest}

The author declares there is no conflict of interest

\section{References}

1. Determinants of financial health.

2. Why financial health is defined as "The dynamic relationship of one's financial and economic resources as they are applied to or impact the state of physical, mental and social well-being."?

3. http://www.financialhealthinstitute.com/financial-health-defined/

4. Influence of finance on health. Studies show that your financial health could be good indicator of your mental health. 2015

5. Amy Morin. Studies show your Financial Health could be a Good Indicator of your Mental Health. 2015.

6. Tips for financial improvement.

7. http://www.macquarie.com/au/personal/financial-advice/expertise/ financial-health-money-management-tips 